\title{
Amylase Measurement
}

National Cancer Institute

\section{Source}

National Cancer Institute. Amylase Measurement. NCI Thesaurus. Code C64434.

A quantitative measurement of amylase present in a sample. 